\title{
Pediatric Dental Emergency Pattern and Dental Care Provided during COVID-19 Pandemic Lockdown at a Tertiary Care Center in Kathmandu,Nepal
}

\author{
Senchhema Limbu, ${ }^{1}$ Parajeeta Dikshit, ${ }^{2}$ Manisha Malla, ${ }^{3}$ Lokesh Verma, ${ }^{4}$ Anju Khapung ${ }^{5}$ \\ ${ }^{1-2}$ Associate Professor, ${ }^{3-5}$ Lecturer, \\ ${ }^{1-3}$ Department of Pedodontics and Preventive Dentistry, ${ }^{4}$ Department of Oral and Maxillofacial Surgery, \\ Kantipur Dental College and Teaching Hospital, Kathmandu Nepal, \\ ${ }^{5}$ Department of Community and Public Health Dentistry, College of Dental Sciences, Nepal Medical College, Jorpati, Kathmandu Nepal.
}

\begin{abstract}
Introduction: Pediatric dental management is difficult in its own way which was even more challenging during COVID-19 outbreak and lockdown period. Constrained dental providing clinics and hospitals severely compromised the pediatric dental needs and services.
\end{abstract}

Objective: The aim of this study was to describe pattern of dental emergencies encountered and services provided to the pediatric patients visiting a dental hospital during the first lockdown period in Kathmandu,Nepal.

Methods: A cross sectional study was done from 24 March 2020 to 21 July 2020 among the pediatric patients who visited dental hospital during lockdown. Data was collected from questionnaire and dental case history sheet,and statistically analyzed in Statistical Package of Social Sciences (SPSS) version 20.

Results: Of the total 172 pediatric patients of mean age $8.3 \pm 2.60$ years,majority were males (59.3\%) and of 6-12 age group (76.2\%). Major complain was mobile/retained teeth (38.4\%) and most common diagnosis was exfoliating mobility (23.3\%). According to American Dental Association (ADA,2020) guidelines, urgent dental care (46.5\%) followed by non-emergency dental care (43.6\%) were mostly found. The predominant procedures were emergency (68.6\%) and least was elective (9.3\%) and treatment given to majority was extraction (51.8\%). There was a statistically significant association between age group and pediatric dental care (ADA).

Conclusions: The findings of this study regarding dental emergency encountered and definitive treatment received even during pandemic lockdown can be helpful in finding out how dental care was provided and can be applicable in similar future pandemics.

Keywords: COVID-19 pandemic, dental care for children, dental emergency, dental problems, lockdown, pediatric dentistry.

\section{INTRODUCTION}

World Health Organization (WHO) declared COVID-19 outbreak as pandemic,foreseeing the risk of this disease whole world was moved into forced lockdown in March $2020 .{ }^{1,2}$ The common transmission routes of it include direct transmission (coughing, sneezing and inhalation of

Correspondence

Dr. Senchhema Limbu

Associate Professor, Department of Pedodontics and Preventive

Dentistry, Kantipur Dental College and Teaching Hospital,

Kathmandu, Nepal

E-mail: senchhe@hotmail.com

Citation

Limbu S, Dikshit P, Malla M, Verma L, Khapung A. Pediatric Dental Emergency Pattern and Dental Care Provided during COVID-19 Pandemic Lockdown at a Tertiary Care Center in Kathmandu, Nepal. J Nepal Assoc Pediatr Dent. 2021;2(1): 3-11 respiratory secretion droplets) and contact transmission (contact with oral, nasal and eye mucous membranes). ${ }^{3}$ Pediatric dentistry is mainly affected since children do not understand the safety protocols of social distancing and personal hygiene measures.

During lockdown most of the hospitals and clinics were closed for weeks due to uncertainty, lack of guidelines ${ }^{4}$ and directives by the governing bodies that directly hampered on health and healthcare utilization specially in dentistry. The American Dental Association (ADA) released a guideline classifying dental emergency and non-emergency during the COVID-19.5 The guidelines were developed for patients of all age groups but pediatric patients and those with special needs experienced pain and dental trauma differing in nature and intensity than 
their adult counterparts; thus successfully managing these emergencies may require different strategies. ${ }^{6}$

This study was conducted on dental emergencies and treatments provided by dental health care professionals following the current ADA guidelines to pediatric patients visiting a dental hospital during COVID-19 pandemic lockdown in Kathmandu,Nepal.

\section{METHODS}

This was a cross sectional study carried out among the pediatric patients during 1st National pandemic lockdown in Kathmandu $\mathrm{Nepal}^{7}$ at Kantipur Dental College and Hospital (KDCH). Ethical approval from Institutional Review Committee of $\mathrm{KDCH}$ was taken. Study was carried out from 24 March 2020 to 21 July 2020 where Modified pediatric dental emergency service was recorded according to American Dental Association (ADA, 2020) ${ }^{5}$ guidelines during the COVID-19 released in the last week of March 2020. According to these guidelines, dental emergencies are categorized as: Dental emergency,urgent dental care,other urgent dental care and non emergency (Table 4) and services provided as emergency,restorative, preventive and elective procedures (Table 5). Census method was used to select the participants visiting the dental hospital during the five months study period.

$\mathrm{KDCH}$ hospital was one of the very few dental centers in Kathmandu to carry out dental emergency services even during the lockdown. In the hospital Department of Oral Medicine and Radiology and Department of Endodontics were named Dental Emergency Department where emergency dental services were provided. All the pediatric patients visiting for emergency dental service were screened for body temperature using an infrared thermometer and peripheral oxygen saturation $\left(\mathrm{SpO}_{2}\right)$ was assessed with pulse oximeter along with their accompanying care persons at the reception. A questionnaire form had to be filled and patients without fever and any apparent symptoms of COVID-19 and $\mathrm{SpO}_{2}$ of $95 \%$ or above were allowed to enter the dental emergency section. Once cleared,pediatric cases between 1-16 years were examined and according to the nature of complaint, signs/symptoms, emergency/non-emergency treatment plan was made and treatment was provided in Dental Emergency Department following the ADA,2020 guidelines which was similar to hospital's guideline. For pediatric patients informed parental consent was obtained for all the patients included in the study prior to treatment.

Based on the nature of the treatment provided,procedures were categorized into emergency, restorative, preventive and elective procedures. They are as follows: ${ }^{8}$

Emergency procedures: Patient who reported with severe acute pain, cellulitis, dentoalveolar abscess and fracture, fall in this category. Treatment procedures included: emergency opening of pulp chamber to relieve pressure/pain, extraction, incision and drainage of abscess,stabilizing fracture/bleeding and splinting of teeth following trauma.

Restorative procedures: Dental caries and its sequels that are not urgent and can be rescheduled or managed with medication until appointment fall under this category. Treatment included: pulpectomy,pulp capping,composite restorations,glass-ionomer cement restorations etc.

Preventive procedures: The treatments required to prevent future dental disease, to reduce the existing risk factors fall under this category. Procedures included: preventive resin restorations, pit and fissure sealants, topical fluoride application,space maintainers etc.

Elective procedure: All procedures which is recommended by the dentist or chosen by the patient that benefits the patient but is not essential currently,fall under this category. Treatments included: orthodontic procedures (jack screws, habit breaking appliances, bite plane), supra and subgingival scaling, aesthetic dental procedures

Parental preference of treatment was assessed by using the ratio of emergency, restorative, preventive, and elective procedures performed according to chief complain and diagnosis of pediatric patients.

Inclusion criteria: All pediatric patients who visited the hospital during the indicated periods and for whom parental consent was obtained

Exclusion criteria: Patients whose parents refused to fill the consent form for participation in the study.

Data was collected through a questionnaire that included: contact history, any symptoms of fever or cough, commuting method and residential location as accurately as possible for each patient. From the Dental Case History 
Records of each patient: Age, chief complain, dental diagnosis, dental care provided were also collected and categorized based on ADA classification. Data collected were entered into Microsoft Excel and Statistical Package of Social Sciences (SPSS) version 20 was used for statistical analysis. Descriptive statistics were expressed in terms of frequency and percentages. Fisher -Freeman Halton Exact Test was used to find the association of pediatric dental care according to ADA with gender and age group. Statistical significance was set at $\mathrm{p}$ value $<0.05$.

\section{RESULTS}

\section{General information}

A total of 172 pediatric patients came for emergency dental treatment in $\mathrm{KDCH}$ during the lockdown period. Socio-demographic data of age group and gender are shown in Figure 1. The age range was 1-16 years old with the mean of $8.3 \pm 2.60$ years. Male to female ratio of 1.5:1 was found in pediatric patients who sought emergency dental treatment. Most of them, 131 (76.2\%) belonged to age group of 6-12 years age (school age child) group.

\section{Purpose of visit}

During lockdown period, most patients visited dental emergency with the chief complain of mobile/retained tooth 66 (38.4\%), dental pain 55 (32\%), extra oral swelling 19 (11\%), dental trauma due to fall $3(1.7 \%)$ and decayed tooth $16(9.3 \%)$ as shown in Table 1.

\section{Diagnosis of the disease}

Oral examination was performed along with investigations

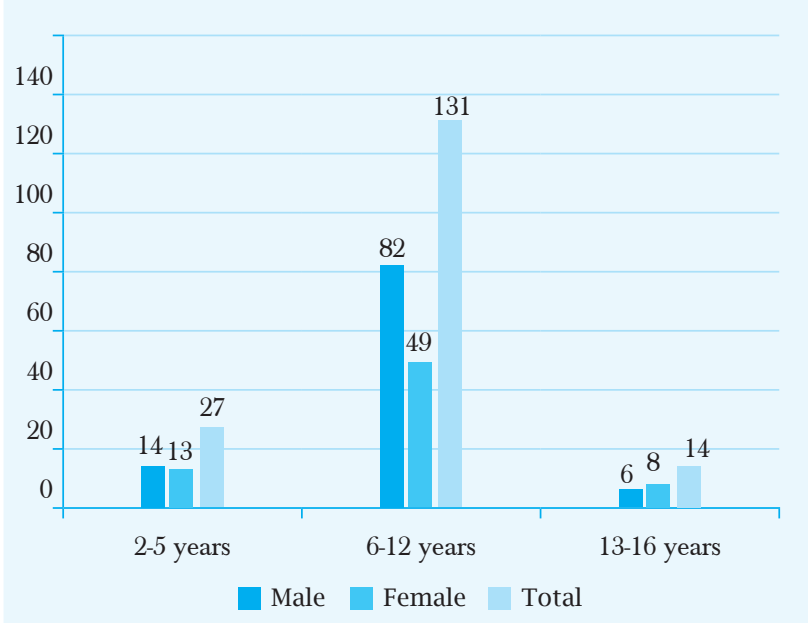

Figure 1. Distribution according to the socio-demographic characteristics of the patients. needed and most common dental emergencies on pediatric patients were diagnosed as exfoliating mobility 40 (23.3\%), acute pulpitis 10 (5.8\%), dental abscess 38 (22.1\%), dental caries 13 (7.6\%), retained tooth 23 (13.4\%) and space infection $2(1.2 \%)$. Various types of diagnoses were grouped by category for descriptive statistics as in Table 2. The proportions of patients with acute toothache and infections were 80 (46.5\%) which was significantly higher than others diagnosis and the remaining 92 (53.5\%) included the proportions of patients with maxillofacial trauma and non-emergencies.

The distribution according to pediatric dental care based on ADA classification is shown in Table 3. The ADA classification of pediatric dental care was done considering the data from the chief complain i.e. purpose of dental visit as in Table 1 and dental diagnosis as in Table 2. According to American Dental Association (ADA,2020) guideline during the COVID-19, pediatric dental care was found as: Urgent dental care 80 (46.5\%), non emergency dental care 75 (43.6\%), other urgent dental care 13 (7.6\%) and emergency dental care 4 (2.3\%). The treatment trend shows the urgent dental care category dominating, followed by non emergency dental care, and the least was emergency dental care.

\section{Pediatric dental visits during lockdown months}

The trend of pediatric dental care from March to May has been presented in Figure 2. It was seen that the cases that needed non emergency care increased from March to May, decreased in June and then increased in July. However those who needed urgent pediatric dental

Table 1. Distribution according to the purpose of visit.

\begin{tabular}{|l|c|c|}
\hline \multicolumn{1}{|c|}{ Complain } & Frequency & Percentage \\
\hline Decayed tooth & 16 & 9.3 \\
\hline Extra oral swelling & 19 & 11.0 \\
\hline $\begin{array}{l}\text { Fall injury/Maxillofacial } \\
\text { trauma }\end{array}$ & 3 & 1.7 \\
\hline Fractured tooth & 2 & 1.2 \\
\hline Mobile/ Retained tooth & 66 & 38.4 \\
\hline Orthodontic problem & 4 & 2.3 \\
\hline Pain & 55 & 32.0 \\
\hline Swelling gums/ Pus discharge & 5 & 2.9 \\
\hline Ulcer & 1 & 0.6 \\
\hline Regular Check up & 1 & 0.6 \\
\hline Total & $\mathbf{1 7 2}$ & $\mathbf{1 0 0}$ \\
\hline
\end{tabular}




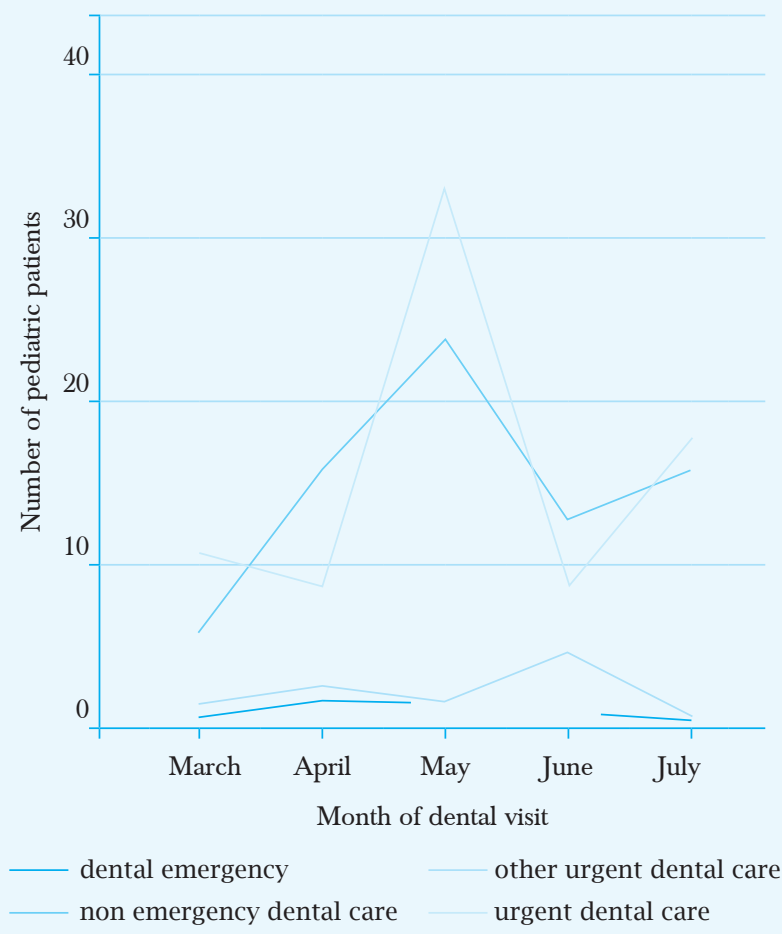

Figure 2. Distribution of pediatric patient's visit and treated from March-July according to ADA classification of pediatric dental care.
Table 2. Distribution of dental diagnosis.

\begin{tabular}{|l|c|c|}
\multicolumn{1}{|c|}{ Diagnosis } & Frequency & Percentage \\
\hline $\begin{array}{l}\text { Dental abscess - Periapical } \\
\text { abscess/Apical periodontitis/ }\end{array}$ & 38 & 22.1 \\
$\begin{array}{l}\text { Dentoalveolar abscess/ } \\
\text { gingival abscess } \\
\text { Acute pulpitis }\end{array}$ & 10 & 5.8 \\
\hline Chronic irreversible pulpitis & 30 & 17.3 \\
\hline Exfoliating mobility & 40 & 23.3 \\
\hline Retained tooth & 23 & 13.4 \\
\hline $\begin{array}{l}\text { Dental caries/ Deep dentinal } \\
\text { caries/ Dislodged restoration/ }\end{array}$ & 13 & 7.6 \\
\hline Reversible pulpitis & & \\
Cystic lesion & 1 & 0.6 \\
\hline Dental trauma & 2 & 1.2 \\
\hline Chronic generalized gingivitis/ & 4 & 2.3 \\
\hline $\begin{array}{l}\text { pericoronitis } \\
\text { Space infection }\end{array}$ & 2 & 1.2 \\
\hline Orthodontic problem & 6 & 3.4 \\
\hline Avulsion & 1 & 0.6 \\
\hline Ulcer & 1 & 0.6 \\
\hline Laceration in upper lip & 1 & 0.6 \\
\hline Total & $\mathbf{1 7 2}$ & $\mathbf{1 0 0}$ \\
\hline & & \\
\hline
\end{tabular}

Table 3. Distribution of study participants according to pediatric dental care based on ADA classification.

\begin{tabular}{|c|c|c|c|}
\hline Category & Treatment & n (\%) & Total n (\%) \\
\hline \multirow{3}{*}{$\begin{array}{l}\text { 1. Dental } \\
\text { Emergency }\end{array}$} & Uncontrolled bleeding & 0 & \multirow{3}{*}{$4(2.3)$} \\
\hline & Cellulitis & $2(50)$ & \\
\hline & Trauma involving facial bones & $2(50)$ & \\
\hline \multirow{9}{*}{$\begin{array}{l}\text { 2. Urgent } \\
\text { Dental Care }\end{array}$} & Severe dental pain from pulpal inflammation & $44(55)$ & \multirow{9}{*}{$80(46.5)$} \\
\hline & Pericoronitis & $3(3.8)$ & \\
\hline & Surgical post-operative osteitis, dry socket dressing changes & 0 & \\
\hline & Abscess,or localized bacterial infection resulting in localized pain and swelling & $29(36.3)$ & \\
\hline & Tooth fracture resulting in pain or causing soft tissue trauma & $2(2.5)$ & \\
\hline & Dental trauma with avulsion/luxation & $1(1.3)$ & \\
\hline & Dental treatment required prior to critical medical procedures & 0 & \\
\hline & $\begin{array}{l}\text { Final crown/ bridge cementation if the temporary restoration is lost,broken or } \\
\text { causing gingival irritation }\end{array}$ & 0 & \\
\hline & Biopsy of abnormal tissue & $1(1.3)$ & \\
\hline \multirow{6}{*}{$\begin{array}{l}\text { 3. Other } \\
\text { Urgent Dental } \\
\text { care }\end{array}$} & Extensive dental caries or defective restorations causing pain & $8(61.5)$ & \multirow{6}{*}{$13(7.6)$} \\
\hline & Manage with interim restorative techniques when possible & $1(7.7)$ & \\
\hline & Suture removal & 0 & \\
\hline & Replacing temporary filling on endo access openings in patients experiencing pain & 0 & \\
\hline & $\begin{array}{l}\text { Snipping or adjustment of an orthodontic wire or appliances piercing or ulcerating } \\
\text { the oral mucosa }\end{array}$ & $3(23.1)$ & \\
\hline & Ulcer & $1(7.7)$ & \\
\hline \multirow{6}{*}{$\begin{array}{l}\text { 4. Non } \\
\text { Emergency } \\
\text { Dental Care }\end{array}$} & Routine Dental Cleaning and preventive procedures & $2(2.7)$ & \multirow{6}{*}{$75(43.6)$} \\
\hline & Orthodontic procedures & $3(4)$ & \\
\hline & Extraction & $65(86.6)$ & \\
\hline & Restorative procedures & $5(6.7)$ & \\
\hline & Aesthetic Dental procedures & 0 & \\
\hline & Aesthetic Dental procedures & 0 & \\
\hline
\end{tabular}


Table 4. Association of pediatric dental care with gender and age group.

\begin{tabular}{|c|c|c|c|c|c|c|}
\hline \multirow{2}{*}{\multicolumn{2}{|c|}{ Variables }} & \multicolumn{4}{|c|}{ ADA classification of pediatric dental care } & \multirow[b]{2}{*}{ p-value } \\
\hline & & $\begin{array}{c}\text { Dental } \\
\text { Emergency } \\
\text { n (\%) }\end{array}$ & $\begin{array}{c}\text { Urgent } \\
\text { Dental Care } \\
\mathbf{n}(\%)\end{array}$ & $\begin{array}{l}\text { Other Urgent } \\
\text { Dental care } \\
\text { n }(\%)\end{array}$ & $\begin{array}{c}\text { Non Emergency } \\
\text { Dental Care } \\
\text { n (\%) }\end{array}$ & \\
\hline \multirow{2}{*}{ Gender } & Male & $1(1)$ & $50(49)$ & $9(8.8)$ & $42(41.2)$ & \multirow{2}{*}{0.40} \\
\hline & Female & $3(4.3)$ & $30(42.9)$ & $4(5.7)$ & $33(47.1)$ & \\
\hline \multirow{3}{*}{ Age group } & Toddlers and preschool & $2(7.4)$ & $19(70.4)$ & $1(3.7)$ & $5(18.5)$ & \multirow{3}{*}{$0.002^{*}$} \\
\hline & School age child & $2(1.5)$ & $56(42.7)$ & $8(6.1)$ & $65(49.6)$ & \\
\hline & Adolescent/ young adult & 0 & $5(35.7)$ & $4(28.6)$ & $5(35.7)$ & \\
\hline & Total & $4(2.3)$ & $80(46.5)$ & $13(7.6)$ & $75(43.6)$ & \\
\hline
\end{tabular}

Fisher - Freeman Halton Exact Test *

Table 5. Pediatric dental procedures classified according to nature of treatment performed.

\begin{tabular}{|c|c|c|c|}
\hline Category & Procedures performed & $\mathrm{n}(\%)$ & Total n (\%) \\
\hline \multirow{8}{*}{ 1. Emergency } & Draining abscess & $15(8.8)$ & \multirow{8}{*}{$118(68.6)$} \\
\hline & Pressure relieving (Emergency access openings) & $7(4.1)$ & \\
\hline & Irrigation and Medication & $1(0.6)$ & \\
\hline & Extraction & $89(51.8)$ & \\
\hline & Orthodontic procedure for pain (due to wire or band impingement) & $3(1.7)$ & \\
\hline & Splinting of teeth following trauma & $1(0.6)$ & \\
\hline & Biopsy & $1(0.6)$ & \\
\hline & Suturing & $1(0.6)$ & \\
\hline \multirow{4}{*}{ 2. Restorative } & Glass Ionomer Cement Restorations & $3(1.7)$ & \multirow{4}{*}{$38(22.1)$} \\
\hline & Pulpectomy & $14(8.1)$ & \\
\hline & Temporary restoration & $2(1.2)$ & \\
\hline & Medication & $19(11)$ & \\
\hline 3. Preventive & Pit and fissure sealant,orthodontic appliances & 0 & \\
\hline \multirow{3}{*}{ 4. Elective } & Orthodontic appliances & $3(1.7)$ & \multirow{3}{*}{$16(9.3)$} \\
\hline & Recall & $9(5.2)$ & \\
\hline & Not willing & $4(2.3)$ & \\
\hline & Total & $172(100)$ & $172(100)$ \\
\hline
\end{tabular}

care showed a decrease from March to April,increased in May, again decreased in June and increased in July. Among those who needed other urgent pediatric dental care, there was an increase from March to April,decrease from April to May and then an increase in June followed by decrease in July. Emergency dental care cases were not seen in May. May month was the month where urgent and non emergency dental care was the most needed.

Pediatric dental care based on ADA classification during the pandemic in 2020

The association of gender and age group with pediatric dental care (ADA) was assessed by Fisher -Freeman Halton Exact Test as in Table 4. No statistically significant association was found between gender and ADA classification of pediatric dental care $(p=0.40)$. There was a statistically significant association between age group and ADA classification of pediatric dental care $(p=0.002)$.
Categorization of treatment according to ADA guidelines

Based on the nature of the treatment given as presented in Table 5, the dental procedures performed were categorized under emergency, restorative, preventive and elective procedures according to $\mathrm{ADA}$ guidelines during the COVID-19. The predominant procedures were emergency 118 (68.6\%) followed by restorative 38 $(22.1 \%)$ and least was elective 16 (9.3\%). No any preventive procedures were undertaken during this period.

Parental preference was assessed using the ratio of emergency,restorative, preventive, and elective procedures performed during the particular lockdown time and it was found to be 7.3:2.3:0:1 respectively. Out of the total, 118 (68.6\%) pediatric patients received the emergency dental treatment and $32(18.6 \%)$ children fell under the nontreatment group and as per the preference of the parents, 
they were kept under medication or were not willing for treatment or were scheduled for recall visits. 19 (11\%) patients went home with drug prescription opting for wait and watch rather than any invasive treatment. Out of the total,140 (81.4\%) received some kind of dental treatment. Among them,extractions 89 (51.8\%) followed by incision and drainage of abscess $15(8.8 \%)$ and pulpectomy 14 (8.1\%) were performed more frequently compared to other treatments such as restorations, orthodontic and traumatic cases.

\section{DISCUSSION}

WHO declared Covid 19 pandemic $^{1}$ and with no exact remedy to control the spread, worldwide lockdown was proclaimed. Many countries focused on its control by announcing and implementing nationwide lockdown including Nepal which underwent 1st National lockdown from 24 March 2020 to 21 July 2020 (120 days). ${ }^{7}$ NDA $^{9}$ also released a guideline not to perform aerosol generating procedures and most of dental clinics and hospitals were closed in Kathmandu. ${ }^{7}$ Samuel SR et al., ${ }^{10}$ reported a study similar to this in Tamil Nadu, India where the Ministry of health and family welfare of the Government of India enforced regulations to curb all dental procedures generating aerosols.

Even during the COVID 19 pandemic $2020 \mathrm{KDCH}$ hospital was functioning with Emergency dental department following standard COVID-19 protocol to provide emergency dental care, although there was a drastic decrease in the number of patients searching for emergency dental care. Study by Humagain $\mathrm{M}$ et al. ${ }^{11}$ showed that only $10 \%$ of the Nepalese dentists were doing dental treatments especially emergency and urgent cases during the lockdown. Ustun $\mathrm{N}$ et al. ${ }^{12}$ observed that there was a decrease in pediatric dental attendance by half during the pandemic period. Similar to our findings, Guo $\mathrm{H}$ et al. $^{13}$ and Tobias $\mathrm{G}$ et al. ${ }^{14}$ also reported decrease in the number of patients visiting the dental emergency clinic in Beijing and Israel respectively.

Participants filled a questionnaire form and those patients without fever and any apparent symptoms of COVID-19 and $\mathrm{SpO}_{2}$ of $95 \%$ or above were allowed to enter the dental emergency section. Similarly, some initiatives such as recording temperature before procedure, avoiding elective dental treatment and teleconsultation were adopted by other dental professionals during this pandemic time. ${ }^{15}$
This COVID-19 pandemic poses threat of rapid transmission making people reluctant to visit public places including medical and dental hospitals. ${ }^{13}$ Due to fear of contacting disease and lesser dental service giving centers pediatric dental patients visited only when required in emergency like dental injury, swelling and severe pain. Our study showed male pediatric patients visited more than female patients. Studies on patients visiting pediatric clinics for dental emergencies have similarly demonstrated that boys were seen more often than girls. ${ }^{8,16-18}$

In this study the common pediatric dental emergencies were with the chief complaint of mobile/retained tooth, dental pain, swelling and dental trauma due to fall. Pediatric patients (32\%) came for emergency treatment with severe dental pain from pulpal inflammation, dental abscess and swelling. Karacin $\mathrm{C}$ et al. ${ }^{19}$ has reported $31.1 \%$ patients approaching pediatric dentist due to pain as in our study. A study by Ustun $\mathrm{N}$ et al. ${ }^{12}$ showed that most of the children exhibited dental pain from pulpal inflammation, abscess and swelling in this pandemic. In a study by Fux-Noy A et al. ${ }^{20}$ it was seen that most of the pediatric patients arrived with emergency such as dental pain, swelling, or dental trauma during the lockdown. Study by Sun $\mathrm{J}$ et al. ${ }^{21}$ showed $83.78 \%$ parents reported with toothache in their children. In a study by Bai J et al. ${ }^{18}$ patients with acute toothaches and infections were significantly higher in 2020. Dental pain is unbearable so seeking dental treatment and getting treated even at the time of pandemic is very common. Dental pain in children can worsen the quality of life of a child especially during the pandemic. ${ }^{10}$

Our study showed that though pediatric patients were brought by their parents for dental treatment, 18.6\% of them underwent only examinations, consultations and oral drug prescription. Out of those who did not receive any invasive treatment (18.6\%) some were given drug prescription $(11 \%)$ as they were not willing to receive any treatment and opted to wait and watch till next visit, and some parents took their children back without any medication for next visit. In a study by Bai J et al., ${ }^{18}$ drug treatment was found to be preferred more as an oral emergency service in 2020 than the endodontic treatment. Antibiotics and analgesics for infection and pain control might be routinely administered to some patients to relieve the symptoms but proper treatment is always needed. 
In this study the most common dental emergency on pediatric patients was diagnosed as exfoliative mobility followed by dental abscess, acute pulpitis and space infection. Similarly in a study by Xia B et al..$^{22}$ the authors found that majority of the patients visited dental hospital with a need to extract primary teeth as an urgent need for treatment. In our study dental emergency i.e. pain (32\%) during this pandemic was mostly from pulpal origin such as acute pulpitis, apical periodontitis and dentoalveolar abscess leading to facial swellings too in some cases. Similarly many studies showed diagnosis as acute pulpitis, apical periodontitis and dental abscess similar to the results of our study. ${ }^{4,12,18,23-26}$ Our study showed dental trauma to be reported less than dental infection similar to a study by Guo $\mathrm{H}$ et al. ${ }^{13}$ in which the authors found dental infection to be $51 \%$ whereas the dental trauma to be $14 \%$. A study by Ustun $\mathrm{N}$ et al. ${ }^{12}$ also showed pediatric visits regarding dental trauma were low during the pandemic. Fux-Noy A et al. ${ }^{20}$ study found $32.3 \%$ of the children diagnosed with dentoalveolar abscess similar to our study where mostly $22.1 \%$ had dentoalveolar abscess during lockdown.

In $\mathrm{KDCH}, \mathrm{ADA} 20205$ guidelines during the COVID were followed and the treatment trend seen in pediatric patients was mostly for the urgent dental care,followed by non emergency dental care, other urgent dental care and emergency procedures. However, this finding was in contrast to a study by Samuel SR et al. ${ }^{14}$ in which the treatment trend was dominated by non emergency procedures, followed by urgent dental care procedures, and the least frequent was emergency procedures. In our study of the multitude of cases treated during the pandemic, only four had dental emergency based on ADA classification ${ }^{5}$ and this is similar to the report by Yang F et al. ${ }^{26}$ and Samuel SR.et al. ${ }^{8}$

In our study,treatments given included extractions (51.8\%) and pulpectomies (8.1\%) performed more frequently during lockdown. Most of the pediatric patients with irreversible pulpitis, dental abscess, dental trauma and exfoliative/ retained teeth underwent extraction while other treatments related to restoration,orthodontic and dental trauma were performed less frequently. Similarly, Fux-Noy A et al. ${ }^{20}$ study in lockdown reported that the treatments included more number of extractions,pulpectomy,pulp extirpation and less permanent restorations during pandemic. Simpson $\mathrm{S}$ et al..$^{27}$ also reported that most of irreversible pulpitis and dental trauma resulted in extractions (49\%). Samuel SR et al. ${ }^{8}$ study showed that extractions predominated the treatments provided to pediatric patients during lockdown. The limitation on aerosol generating dental treatments with precautions and uncertainty about the span of lockdown made the dentists to take more radical treatments such as extractions during this period. Pain and its association leading to increase in number of extractions reflect the severity of the dental condition by pain that led the patients to come for emergency dental treatment.

In $\mathrm{KDCH}$ during pandemic lockdown, though aerosol producing procedures were stopped some emergency opening of tooth and pulpectomies needed to be performed for pain management but still restorations were done less in number. Likewise in a study by Ustun $\mathrm{N}$ et al. ${ }^{12}$ the authors showed that non emergency routine dental visits had exhibited a drastic decline during the pandemic. Similarly, Al-Halabi et al. ${ }^{28}$ also suggested minimally invasive treatments to be used for caries management to minimize aerosol generating procedures so as to minimize viral cross-infection.

In our study after extraction, emergency access opening, pulpectomy and incision and drainage were the most frequent procedures done for dentoalveolar abscess and acute pulpitis. Similarly study by Farmakis ET et al. ${ }^{25}$ also showed pulpectomy as the most common treatment in emergency dental care to effectively alleviate the symptoms of acute pulpitis. In a recent survey done in United Kingdom (UK) during COVID-19 lockdown in 2020, it has been found that number of patients with space infections requiring incision and drainage had increased during lock down. ${ }^{29}$ A study done at tertiary care centre in UK found that $84 \%$ of the emergency dental patients during Covid-19 pandemic were related with dentoalveolar surgery followed by trauma. ${ }^{30}$

In our study, according to $\mathrm{ADA}^{5}$ guidelines, treatment provided procedures are categorized as emergency, restorative, preventive and elective. The predominant procedure performed was emergency followed by restorative while no patients underwent preventive procedures unlike the study by Samuel SR et al. ${ }^{8}$ in which the predominant procedures was restorative and least was elective. Similarly Ustun $\mathrm{N}$ et al., ${ }^{12}$ their study also showed dental non emergency care visit reasons (elective 
procedures and restorative dentistry) to be less common in pandemic period compared to the non-pandemic period.

The outcomes of our study provides a few insights into the various dental problems encountered by pediatric patients during lockdown and the types of procedures performed to relieve the dental pain the children were having during the pandemic. Limitation of the study was, it's a single center study and follow up of every pediatric patient treated during the pandemic could not be done. It was difficult to provide service at this crucial hour and management of children is different than adult but children's oral health is crucial and it was achieved by following safety protocols and guidelines even during pandemic lockdown.

\section{CONGLUSIONS}

The COVID-19 pandemic lockdown had a substantial impact on the dental emergency services. Even during the lockdown period, pediatric patients experienced dental emergencies like dental pain, swelling and dental trauma prompting them to visit a dental facility and receive immediate dental care. Clinics and hospitals can operate more smoothly by careful planning,management and execution of oral health care following national and international guidelines during times of need. The findings of this study can be used to forecast and anticipate future dental needs and their management in the event of similar pandemics in the future.

\section{AGKNOWLEDGEMENTS}

I would like to thank all the parents, children, doctors and management team of $\mathrm{KDCH}$ who made this study possible.

Conflict of Interest: None

\section{REFERENGES}

1. Mahase E. China coronavirus: WHO declares international emergency as death toll exceeds 200. BMJ. 2020 Jan 31;368:m408. [리 Med | Full Text | DOI].

2. World Health Organization. Retrieved 16 Jan 2021. Available from: https://www.who.int/. [Link]

3. Lu CW,Liu XF,Jia ZF. 2019-nCoV transmission through the ocular surface must not be ignored. Lancet. 2020 Feb 22;395(10224):e39. [피 Med I Full Text | DOI]

4. Grossman S,Sandhu P,Sproat C,Patel V. Provision of dental services at a single institution in the UK's epicentre during the COVID-19 pandemic. Br Dent J. 2020 Jun;228(12):964-970. [PubMed | Full Text | DOI]

5. American Dental Association. What Constitutes A Dental Emergency?. Retrieved 16 Jan 2021. Available from: Available at: https://www.ada.org/en/publications/ ada-news/2020-archive/march/ada-develops-guidance-on-dental-emergency-nonemergency-care. [Full Text I Link]

6. Mallineni SK,Innes NP,Raggio DP,Araujo MP,Robertson MD,Jayaraman J. Coronavirus disease (COVID-19): Characteristics in children and considerations for dentists providing their care. Int J Paediatr Dent. 2020 May;30(3):245-250. [ [PubMed | Full Text | DOI]

7. Pradhan,T R. Government decides to lift the four-month-long coronavirus lockdown,but with conditions. The Kathmandu Post.2020 July 21 . Retrieved 16 Jan 2021. Available from: https://web.archive.org/web/20200722121600/https:/kathmandupost.com/national/2020/07/21/government-decides-to-lift-the-four-month-longcoronavirus-lockdown-but-with-conditions. [Link]

8. Samuel SR,Mathew MG,Suresh SG,Varma SR,Elsubeihi ES,Arshad F,Elkareimi Y,Elsahn NA,Khalil E. Pediatric dental emergency management and parental treatment preferences during COVID-19 pandemic as compared to 2019. Saudi J Biol Sci. 2021 Apr;28(4):2591-2597. [PubMed | Full Text I DOI]

9. Nepal Dental Association. INTERIM GUIDANCE FOR DENTAL PRACTICES DURING COVID 19 GLOBAL EMERGENCY IN NEPAL. Retrieved 16 Jan 2021. Available from: https://nda.org.np/erp//UploadedFiles/DocImages/5.pdf. [Full Text I Link]]

10. Samuel SR,Kuduruthullah S,Khair AMB,Shayeb MA,Elkaseh A,Varma SR. Dental pain,parental SARS-CoV-2 fear and distress on quality of life of 2 to 6 yearold children during COVID-19. Int J Paediatr Dent. 2021 May;31(3):436-441. [PubMed | Full Text | DOI]

11. Humagain M,Humagain R, Rokaya D. Dental Practice during COVID-19 in Nepal: A Descriptive Cross-sectional Study. JNMA J Nepal Med Assoc. 2020 Oct;58(230):764-9. [리Med | Full Text | DOI]

12. Ustun N,Akgol BB,Bayram M. Influence of COVID-19 pandemic on paediatric dental attendance. Clin Oral Investig. 2021 Mar 30:1-7. [PubMed | DOI]

13. Guo HZhou Y,Liu X,Tan J. The impact of the COVID-19 epidemic on the utilization of emergency dental services. J Dent Sci. 2020 Dec;15(4):564-567. [PubMed | Full Text | DOI]

14. Tobias G, Findler M, Bernstein Y, Meidan Z, Manor L, Mann J. Dental emergencies during the COVID-19 no aversion therapy centers. J Dental Sci. (2020) 5:000265. 10.23880/OAJDS-16000265. [Full Text | DOI]

15. Seymour CW, Kennedy JN, Wang S, Chang CH, Elliott CF, Xu Z, Berry S, Clermont G, Cooper G, Gomez H, Huang DT, Kellum JA, Mi Q, Opal SM, Talisa V,van der Poll T,Visweswaran S,Vodovotz Y,Weiss JC, Yealy DM, Yende S, Angus DC. Derivation, Validation, and Potential Treatment Implications of Novel Clinical Phenotypes for Sepsis. JAMA. 2019 May 28;321(20):2003-2017. [PubMed I DOI]

16. Yeng T,Parashos P. Dentists' management of dental injuries and dental trauma in Australia: a review. Dent Traumatol. 2008 Jun;24(3):268-71. [PubMed | DOI]

17. Naidu RS,Boodoo D,Percival T,Newton JT. Dental emergencies presenting to a university-based paediatric dentistry clinic in the West Indies. Int J Paediatr Dent. 2005 May;15(3):177-84. [PubMed | DOI]

18. Bai J,Xu TJi AP,Sun W,Huang MW. Impact of COVID-19 on oral emergency services. Int Dent J. 2020 Jul 2. [리 Pul I Full Text I DOI]

19. Karacin C,Bilgetekin I,B Basal F,Oksuzoglu OB. How does COVID-19 fear and anxiety affect chemotherapy adherence in patients with cancer. Future Oncol. 2020 Oct;16(29):2283-2293. [PubMed | Full Text | DOI] 
20. Fux-Noy A,Mattar L,Shmueli A,Halperson E,Ram D,Moskovitz M. Oral Health Care Delivery for Children During COVID-19 Pandemic-A Retrospective Study. Front Public Health. 2021 May 7;9:637351. [ubMed I DOI]

21. Sun J,Xu Y,Qu Q,Luo W. Knowledge of and attitudes toward COVID-19 among parents of child dental patients during the outbreak. Braz Oral Res. 2020 Jun 8;34:e66. [PubMed | DOI]

22. Xia B,Ge LH,Wang ZG, et al. Conditions analysis for 256 children patients in emergency Department of Peking University Hospital of Stomatology. J Modern Stomatol 2006;20:214-215. [Link]

23. Tramini P,Al QadiNassar B,Valcarcel J,Gibert P. Factors associated with the use of emergency dental care facilities in a French public hospital. Spec Care Dentist. 2010 Mar-Apr;30(2):66-71. [PubMed | DOI]

24. Huang JY, Yu HC, Chen YT, Chiu YW, Huang SM, Chang YC. Analysis of emergency dental revisits in Taiwan (1999-2012) from Taiwanese National Health Insurance Research Database (NHIRD). J Dent Sci. 2019 Dec;14(4):395-400. [피Med | DOI]

25. Farmakis ET,Palamidakis FD,Skondra FG,Nikoloudaki G,Pantazis N. Emergency care provided in a Greek dental school and analysis of the patients' demographic characteristics: a prospective study. Int Dent J. 2016 Oct;66(5):280-6. [uㅣㄹed I DOI]

26. Yang F,Yu L,Qin D,Hua F,Song G. Online consultation and emergency management in paediatric dentistry during the COVID-19 epidemic in Wuhan: A retrospective study. Int J Paediatr Dent. 2021 Jan;31(1):5-11. [PubMed | Full Text | DOI]

27. Simpson S,Sumner O,Holliday R,Currie CC,Hind V,Lush N,et al. Paediatric Dentistry and the coronavirus (COVID-19) response in the North East of England and North Cumbria. Medrxiv and bioRxiv [preprint]. (2020). 10.1101/2020.06.02.20114967. [Full Text | DOI]

28. Al-Halabi M,Salami A,Alnuaimi E,Kowash M,Hussein I. Assessment of paediatric dental guidelines and caries management alternatives in the post COVID-19 period. A critical review and clinical recommendations. Eur Arch Paediatr Dent. 2020 Oct;21(5):543-556. [PubMed | Full Text | DOI]

29. Politi I, McParland E, Smith R, Crummey S,Fan K. The impact of COVID-19 on cervicofacial infection of dental aetiology. Br J Oral Maxillofac Surg. 2020 Oct;58(8):1029-1033. [PubMed | Full Text | DOI]

30. Pajpani M,Patel K,Bendkowski A,Stenhouse P. Rapid response: activity from a hospital based Urgent Dental Care Centre during the COVID-19 pandemic. Br J Oral Maxillofac Surg. 2020 Nov;58(9):e98-e103. [ㅂubMed | Full Text | DOI] 